\title{
Investigation of seasonal and interannual variability of water exchange through the Middle Caspian based on satellite altimetry
}

\author{
S. A. Lebedev ${ }^{1,3}$, A. G. Kostianoy ${ }^{2,4,5}$ \\ ${ }^{1}$ Geophysical Center, Russian Academy of Sciences, Moscow, 119296, Russia \\ ${ }^{2}$ Shirshov Institute of Oceanology, Russian Academy of Sciences, Moscow, 117997, \\ Russia \\ ${ }^{3}$ Maykop State Technological University, Maykop, 385000, the Republic of Adygea, \\ Russia \\ ${ }^{4}$ Witte Moscow University, Moscow, 115432, Russia \\ ${ }^{5}$ Space Research Institute, Russian Academy of Sciences, Moscow, 117997, Russia \\ E-mail: lebedev@wdcb.ru
}

\begin{abstract}
Seasonal and interannual variability of water exchange between the Northern and Middle (133 track), and Middle and Southern (209 track) Caspian Sea was calculated based on satellite altimetry data of TOPEX/Poseidon and Jason-1, -2, -3 satellites for 1992-2018. The climatic value of water exchange through the 133 track was $+0.41 \mathrm{~Sv}$, and through the 209 track $+0.37 \mathrm{~Sv}$. The difference can be explained by the evaporation of water and the recirculation in the Middle Caspian cyclonic gyre. The maximum negative water exchange anomaly of $-0.147 \mathrm{~Sv}$ occurs on average in August while the maximum positive water exchange anomaly of $+0.112 \mathrm{~Sv}$ occurs in February. Since 2005 anomalies of water exchange through the Middle Caspian fluctuates from $+0,013 \mathrm{~Sv}$ (2006) to $-0,017 \mathrm{~Sv}$ (2008), i. e. the amplitude of interannual variability of water exchange became five times less than in 1992-2005. This is an interesting observation which means that after 2005 in the course of the continuous sea level drop water exchange through the Middle Caspian from year to year became much more stable.
\end{abstract}

Accepted: 15.09 .2020

DOI: 10.21046/2070-7401-2020-17-6-103-109

\section{Introduction}

The Caspian Sea is the world's largest enclosed water body, the level of which is $28.0 \mathrm{~m}$ below ocean level. Its isolation from the oceans distinguishes it from inland and marginal seas. All other signs of the Caspian Sea: dimensions, depths, features of the thermohaline structure and water circulation allow us to attribute it to the type of deep inland seas [1]. According to geomorphological and hydrometeorological conditions, the Caspian Sea is conditionally divided into three parts: The Northern, Middle and Southern Caspian Sea (figure 1a).

In the incoming part of the water balance, river runoff averages $74-85 \%$. More than $85 \%$ of the river runoff belongs to the Northern Caspian (the coast of the Russian Federation: Volga River $-80 \%$, Terek River $-3 \%$, Kazakhstan coast: Ural River - 3\%, Emba River - less than $1 \%)[1,2]$. Up to $90 \%$ of the total amount of pollution enters the Caspian Sea with river runoff. Annually, $2.5 \mathrm{~km}^{3}$ of untreated and $7 \mathrm{~km}^{3}$ of conditionally treated wastewater are discharged into the Volga Basin. Shipping and oil transportation by the sea are another source of pollution of the Caspian. Significant sources of pollution of the Caspian are offshore oil fields in Russia, Kazakhstan, Azerbaijan and Turkmenistan [2]. 


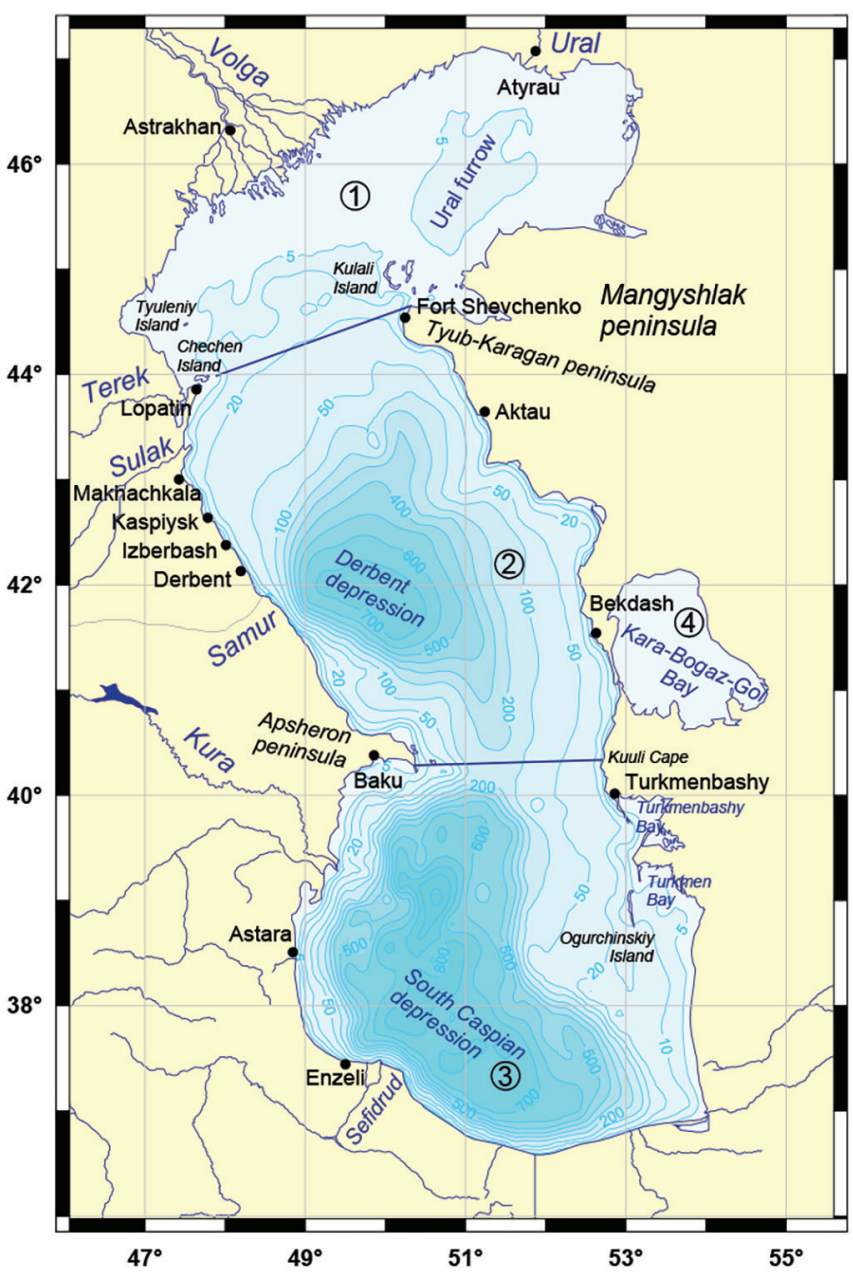

Figure 1. The Caspian Sea. Main parts of the Caspian Sea: (1) - the Northern Caspian; (2) - the Middle Caspian; (3) - the Southern Caspian; (4) - the Kara-Bogaz-Gol Bay. Isobaths are shown in meters according to Digital Elevation Model "Caspy-30 seconds". The coastline corresponds to year 1934, when the Caspian Sea level was $-26.46 \mathrm{~m}$ relative to the World Ocean [3].

One of the mechanisms for the spread of pollutants in the sea is water circulation, and hence the water exchange between parts of the Caspian Sea. The Caspian Sea washes the shores of five coastal states: the Russian Federation, Kazakhstan, Azerbaijan, Turkmenistan and Iran. For this reason, the issue of water exchange between different parts of the Caspian Sea takes on the character of an assessment of transboundary pollution transfer, which is especially important and relevant after the signing of the Convention on the Legal Status of the Caspian Sea in August 2018.

\section{Water exchange between different parts of the Caspian Sea}

Currently, the only source of knowledge about the water circulation in the Caspian Sea and the exchange between its parts is numerical modeling based on thermohydrodynamic models using temperature and salinity 3D fields and atmospheric forcing [3]. In [5, 6] it was shown that the operational hydrodynamic model of the Caspian Sea can be used to assess the transboundary transport of pollutants at the border of the Russian sector of the Caspian Sea.

However, calculations using any numerical model may contain errors, and the results may differ from the true values. Regular measurements of current velocities in situ are very expensive and in certain cases even impossible because water area belongs to five littoral states. The experience of using remote sensing data, in particular satellite altimetry, to analyze the circulation of the Caspian Sea is well known [3, 4, 7-9]. For this reason, it is proposed to use satellite altimetry data to study the seasonal and interannual variability of water exchange between different parts of the Caspian Sea.

\subsection{Data}

To analyse changes in water exchange between parts of the Caspian Sea, altimetry measurements from TOPEX/Poseidon and Jason-1, -2, -3 satellites in 1992-2018 were used for the following reasons. The accuracy of measurements of the sea surface height $(\mathrm{SSH})$ of these satellites is $1.7 \mathrm{~cm}$, 
which exceeds the accuracy of other altimetry programs. At the same time, the accuracy of measuring sea level is about $4 \mathrm{~cm}$, which is sufficient for this research. The orbit repetition period (about 10 days) allows us to analyze the interannual and seasonal variability of sea level and currents $[3,4$, 7-9]. The spatial resolution of sea level measurements by these satellites is better than the typical Rossby radius of deformation for the Caspian Sea $(7.5-10 \mathrm{~km})$ [4, 7]. The TOPEX/Poseidon satellite data represents the longest time series of measurements of sea level anomalies (SLA) (September 1992 - August 2002 or 1-364 cycle) with the possibility of supplementing the series with Jason-1 data (August 2002 - January 2009 or 1-259 cycle), data from Jason-2 (August 2008-October 2016 or $1-303$ cycle), and data from Jason-3 (February 2008 - present) on the same ground tracks.

Positions of the 133 and 209 TOPEX/Poseidon and Jason-1, -2, -3 satellite tracks (figure 2a) are optimal for analysing water exchange between parts of the Caspian Sea, although they do not coincide with the geographical boundaries of the Northern, Middle and Southern Caspian. However, for this part of the Caspian Sea, limited to 133 and 209 tracks, there is no river runoff, and the runoff to KaraBogaz-Gol Bay is located south of track 209. To calculate the water exchange through sections corresponding to positions of the 133 and 209 TOPEX/Poseidon and Jason-1, -2, -3 satellite tracks, the Digital Elevation Model "Caspy-30 seconds" was used [10] (figure 2).
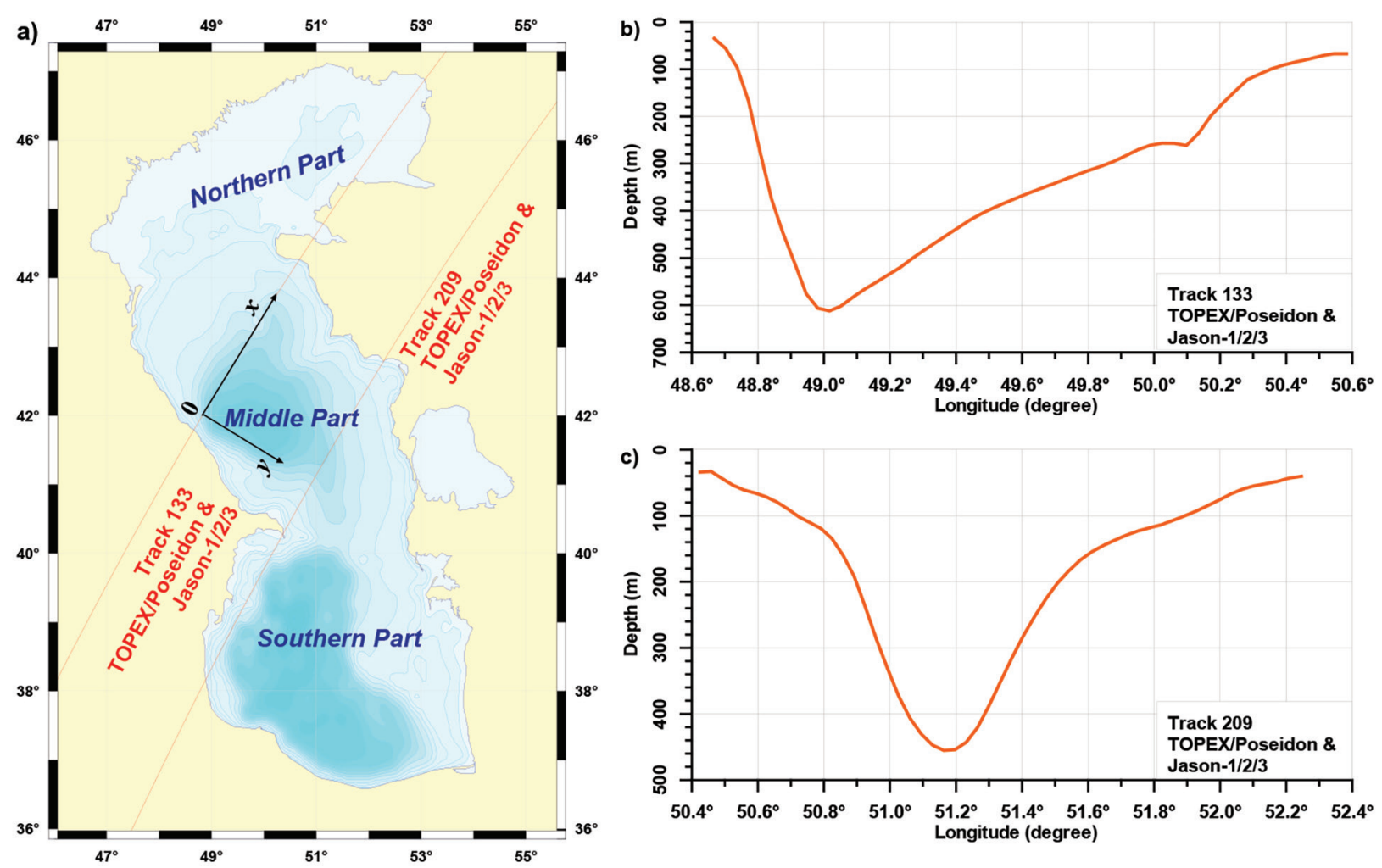

Figure 2. Bottom topography according to Digital Elevation Model "Caspy-30 seconds" and position of the 133 and 209 tracks of the TOPEX/Poseidon and Jason-1, -2, -3 satellites on water area of the Caspian Sea, and coordinate axes for calculation water exchange across these tracks (a); bottom topography (m) along these tracks (b), (c).

The calculation of the sea level anomalies (SLA) was carried out relative to the model of mean sea surface heights (MSS) of the Caspian Sea (named as CS_MSS_GCRAS19), developed at the Geophysical Center of the Russian Academy of Sciences, which takes into account interannual variability of the Caspian Sea level [11, 13].

\subsection{Method}

In order to calculate the water exchange through the track, we need to know the normal component of current velocity to it over the entire depth. According to the geostrophic approximation, the zonal component of the surface current velocity $u_{y}$ (along the abscissa axis) is defined as: 


$$
\left.u_{y}\right|_{z=0}=\frac{g}{f} \cdot \frac{\partial h_{d y n}}{\partial x}
$$

where $g$ is the acceleration of gravity, $f$ is the Coriolis parameter, $h_{d y n}$ is the dynamic topography. If we rotate the coordinate axes so that the ordinate axis coincides with the direction along the 133 and 209 tracks, and the abscissa axis is directed to the southeast, then the dynamic topography gradient will correspond to the component of the velocity of surface currents directed perpendicularly through the tracks (figure 2a). A positive value for the 133 track corresponds to the direction of water exchange from the Northern part of the Caspian Sea to the Middle part, negative, on the contrary, and for the 209 track positive value - from the Middle Caspian to the Southern Caspian and vice versa for negative values. The water exchange component through the track is calculated as follows:

$$
U_{y}=\int_{x_{0}}^{x_{n}} \int_{0}^{H} u_{y} \mathrm{~d} z \mathrm{~d} x,
$$

where $x_{0}$ - ordinate of the beginning of the track, $x_{n}$ - ordinate of the end of the track, $H$ - depth of the sea along the track. Wherein $x_{n}-x_{0}=L-$ is a length of the track which cross the Caspian Sea.

At the sea surface $(z=0)$ velocity of currents is determined from the geostrophic relationship (1), at the bottom $(z=H)$ - from sticking condition:

$$
\left.u_{y}\right|_{z=H}=0 \text {. }
$$

To work with satellite altimetry data, dynamic topography in equation (1) should be considered as:

$$
h_{d y n}=\overline{h_{d y n}}+\Delta h_{d y n}
$$

where $\overline{h_{d y n}}$ - average climatic dynamic topography, a $\Delta h_{d y n}$ - anomaly of dynamic topography, which is associated with sea level anomalies calculated according to satellite altimetry data as the deviations of the sea surface height (SSH) from the average height of the sea surface (MSS) which includes the average climatic dynamic topography:

$$
\Delta h_{d y n}=\mathrm{SLA}=\mathrm{SSH}-\mathrm{MSS} .
$$

Thus, water exchange anomalies $\Delta U_{y}$ through the track will be calculated via the anomalies of velocity $\Delta u_{y}$ as:

$$
\Delta U_{y}=\int_{x_{0}}^{x_{n}} \int_{0}^{H} \Delta u_{y} \mathrm{~d} z \mathrm{~d} x
$$

taking into account the boundary conditions (1) and (3), which take the following form:

$$
\left.\Delta u_{y}\right|_{z=0}=\frac{g}{f} \cdot \frac{\partial \Delta h_{d y n}}{\partial x} \text { and }\left.\Delta u_{y}\right|_{z=H}=0 .
$$

Accordingly, the anomalies of total water exchange through the Middle Caspian associated with water exchange through the 133 and 209 tracks were calculated as follows:

$$
\left.\Delta U_{y}\right|_{\text {Middle Csapian }}=\left.\Delta U_{y}\right|_{133 \text { track }}-\left.\Delta U_{y}\right|_{209 \text { track }} .
$$

\section{Results}

\subsection{Average or climatic water exchange}

To calculate the average or climatic value of the water exchange through each track, we use the average dynamic topography calculated using the three-dimensional baroclinic hydrodynamic model with a free surface developed at the Laboratory of Marine Applied Research of the Hydrometeorological Center of Russia [13] (figure 3). Based on equation (2) with boundary conditions (1) and (3), the climatic value of water exchange through the 133 track was $+0.41 \mathrm{~Sv}$, and through the 209 track $+0.37 \mathrm{~Sv}$. Thus, in the Middle Caspian, the amount of water exchange through its southern border (209 track) is 
by $0.04 \mathrm{~Sv}$ less than through its northern border. This can be explained by the evaporation of water and the recirculation in the Middle Caspian cyclonic gyre (figure 3a).
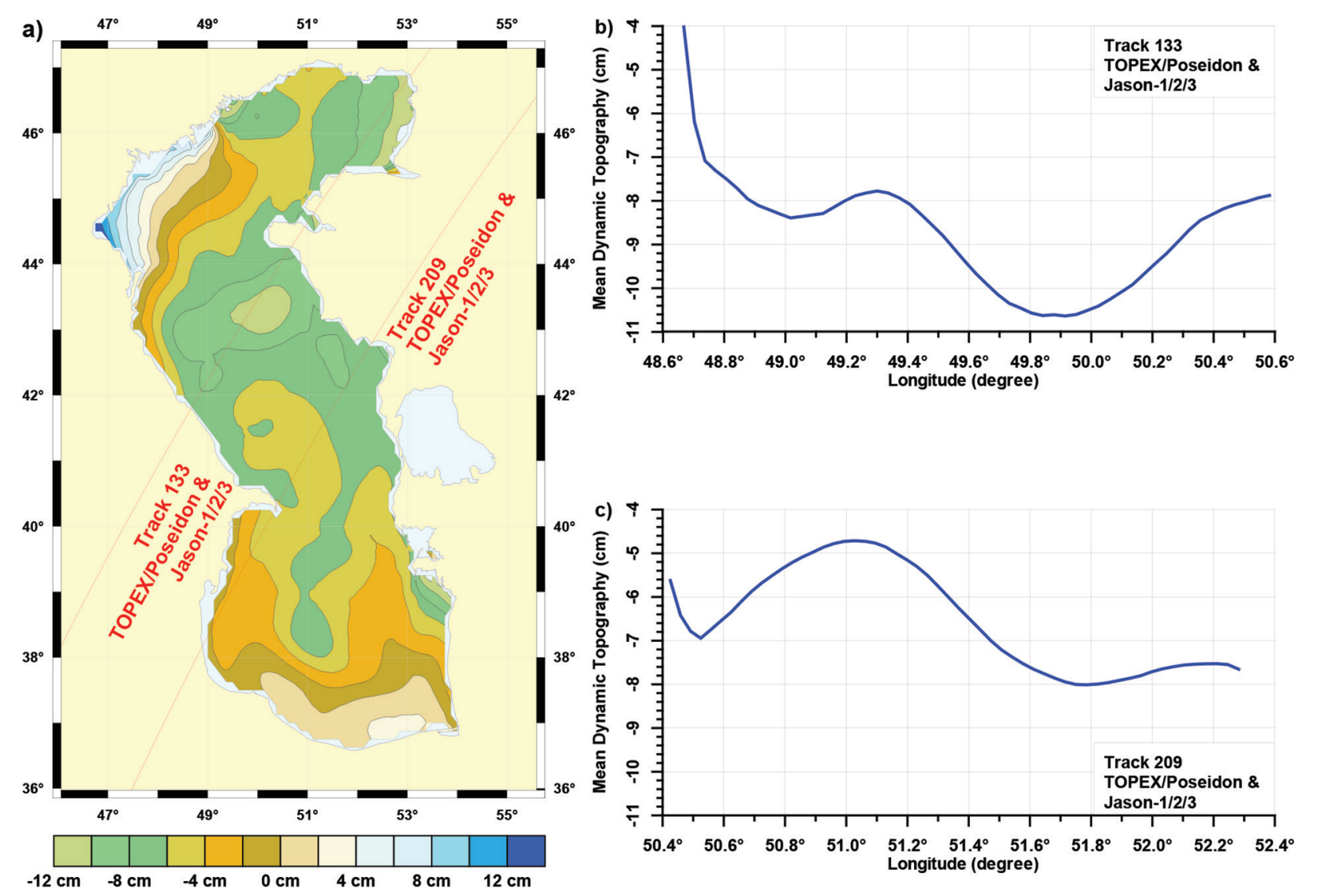

Figure 3. Mean dynamic topography $(\mathrm{cm})$ calculated by hydrodynamic model of the Laboratory of Marine Applied Research of the Hydrometeorological Center of Russia and position of the 133 and 209 tracks of the TOPEX/Poseidon and Jason-1, -2, -3 satellites on water area of the Caspian Sea (a); mean dynamic topography (cm) along the 133 and 209 tracks (b), (c).

\subsection{Water exchange anomalies}

Water exchange anomalies were calculated along the 133 and 209 tracks using equation (6) and boundary conditions (7) for each cycle of altimetry measurements of TOPEX/Poseidon and Jason-1, -2, -3 satellites, the repetition period of which was about 10 days. The calculation results for the time period 1992-2018 show that water exchange through the Middle Caspian has notable seasonal and interannual variability (figure 4). The maximum negative water exchange anomaly of $-0.147 \mathrm{~Sv}$ occurs on average in August simultaneously with the maximum sea level in this part (figure 4c). This can be explained by different rate of evaporation and changes in the circulation patterns in the Northern, Middle and Southern Caspian. The maximum positive water exchange anomaly of $+0.112 \mathrm{~Sv}$ occurs on average in February. This is likely due to the strengthening of the general cyclonic circulation in the sea, especially along the eastern shores, which leads to the flow of water from the Southern Caspian to the Middle and then to the Northern Caspian.

In the interannual variability of anomalies of water exchange through the Middle Caspian (figure 4b), periods are observed when negative water exchange anomalies (1996-1997, 2000-2001) and positive water exchange anomalies $(1998-1999,2002)$ predominate. In 1998 we have observed a maximum anomaly of $+0.069 \mathrm{~Sv}$ and in 2000 a minimum anomaly of $-0.079 \mathrm{~Sv}$. Since 2005 anomalies of water exchange through the Middle Caspian fluctuates from $+0,013 \mathrm{~Sv}$ (2006) to $-0,017 \mathrm{~Sv}$ (2008), i.e. the amplitude of interannual variability of water exchange anomaly became five times less than in 1992-2005 (figure 4b). This is an interesting observation which means that after 2005 in the course of the continuous sea level drop water exchange through the Middle Caspian from year to year became much more stable. 

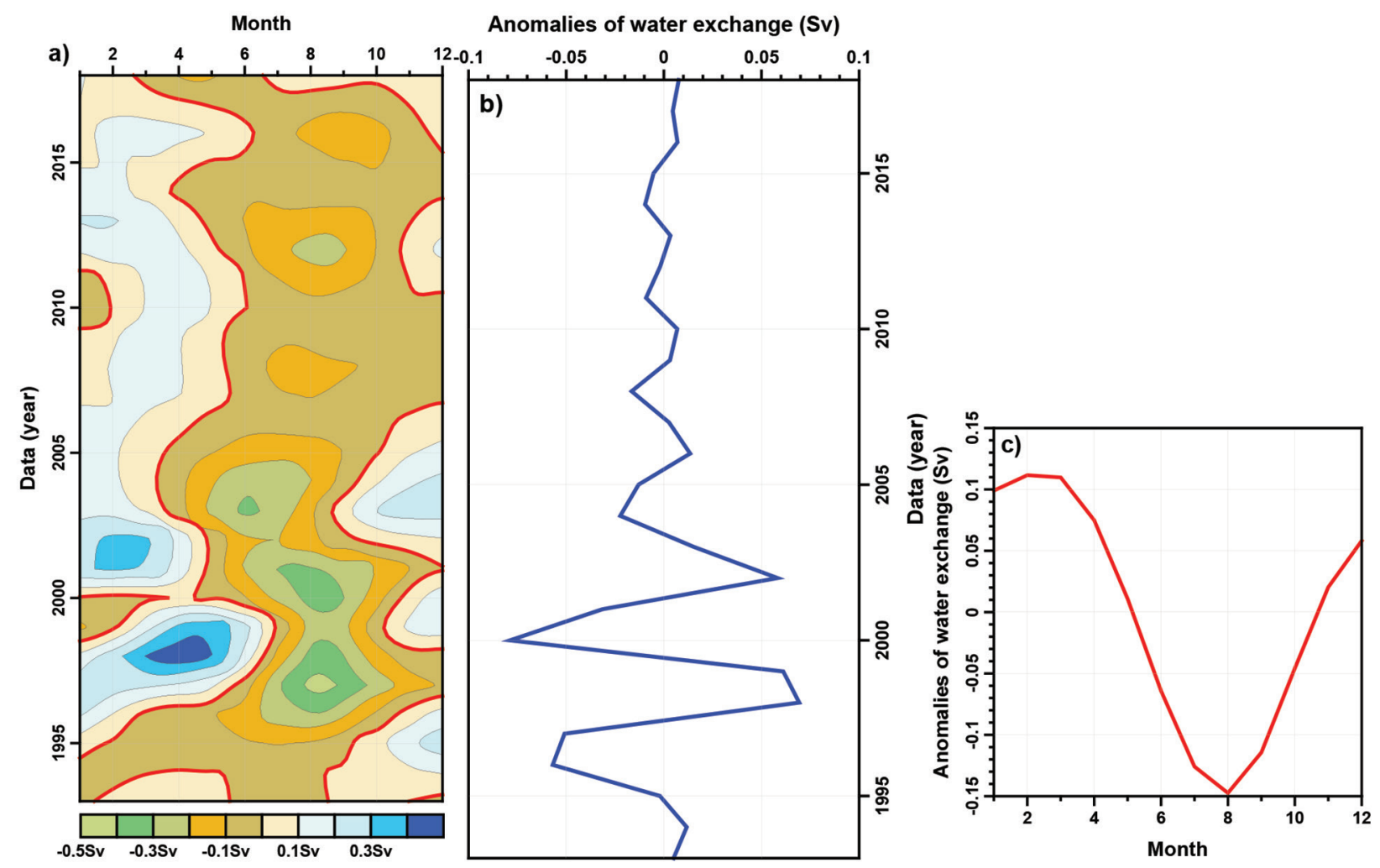

Figure 4. Temporal variability of anomalies of water exchange (Sv) through the Middle Caspian, calculated on the base of altimetry data of TOPEX/Poseidon and Jason-1, -2, -3 satellites. Red line corresponds to zero water exchange anomaly (a); interannual variability of anomalies of water exchange (Sv) through the Middle Caspian (b); seasonal variability of anomalies of water exchange (Sv) through the Middle Caspian (c).

\section{Conclusion}

In this presentation we continue our exercises in application of satellite altimetry data to reconstruction and investigation of seasonal and interannual variability of circulation patterns in the Caspian Sea $[4,9]$, the Volga flood wave propagation along the western coast of the sea [14], and water exchange analysis between different parts of the Caspian Sea [15]. The obtained results seem to be very realistic and promising in application for other inland seas and regions of the World Ocean where ground tracks of the altimetry satellites cross water areas perpendicular to water exchange between neighbouring basins. To confirm the reliability of the developed methodology our next steps will be focused on the comparison of water exchange values between different parts of the Caspian Sea obtained from satellite altimetry with those obtained along the same ground tracks but derived from 3D baroclinic hydrodynamic models elaborated in the Institute of Numerical Mathematics of Russian Academy of Sciences and at the Laboratory of Marine Applied Research of the Hydrometeorological Center of Russia.

\section{Acknowledgements}

S. A. Lebedev (satellite altimetry data processing and analysis) was supported in the framework of the Geopphysical Center RAS budgetary financing (Project No. 0145-2019-0004). A. G. Kostianoy (an analysis of seasonal and interannual variability of water exchange) was supported by the Russian Science Foundation (Project No. 19-77-20060).

\section{References}

[1] The Caspian Sea Environment, Kostianoy A. G., Kosarev A.N. (eds.), Berlin; Heidelberg; New York: Springer-Verlag, 2005, $271 \mathrm{p}$.

[2] Water balance and level fluctuations of the Caspian Sea. Modelling and prediction, E. S. Nesterov (ed.), Moscow: TRIADA Ltd., 2016, 378 p. 
[3] Lebedev S.A., Kostianoy A.G., Integrated using of satellite altimetry in investigation of meteorological, hydrological and hydrodynamic regime of the Caspian Sea, Terrestrial, Atmospheric and Oceanic Sciences, 2008, Vol. 19(1-2), pp. 71-82.

[4] Lebedev S., Climatic variability of water circulation in the Caspian Sea based on satellite altimetry data, Intern. J. Remote Sensing, 2018, Vol. 39(13), pp. 4287-4292.

[5] Popov S. K., Numerical simulation of current velocities and sea-level of the Russian seas, Proc. State Oceanographic Institute by N. N. Zubov, 2014, Vol. 215, pp. 40-52.

[6] Monakhova G.A., Popov S. K., Asaeva K. I., Rakhimbirdiev N. I., New method to estimate pollutants balance in marine water area allotted for exploration and production of hydrocarbons, South of Russia: Ecology, Development, 2016, Vol. 11(1), pp. 128-136.

[7] Lebedev S.A., Kostianoy A. G., Satellite Altimetry of the Caspian Sea, Moscow: MORE, 2005, 484 p.

[8] Kouraev A.V, Crétaux J.-F., Lebedev S. A., Kostianoy A. G., Ginzburg A. I., Sheremet N. A., Mamedov R., Zakharova E. A., Roblou L., Lyard F., Calmant S., Bergé-Nguyen M., Satellite Altimetry Applications in the Caspian Sea, Coastal altimetry, Berlin, Heidelberg: Springer, 2011, pp. 331-366.

[9] Lebedev S.A., Dynamics of the Caspian Sea based on satellite altimetry data, Sovremennye problemy distantsionnogo zondirovaniya Zemli iz kosmosa, 2015, Vol. 12(4), pp. 72-85.

[10] Bolgov M. V., Krasnozhon G. F., Lyubushin A. A., The Caspian Sea: Extreme Hydrological Events, Moscow: Nauka, 2007, 381 p.

[11] Lebedev S.A., Mean Sea Surface Model of the Caspian Sea Based on TOPEX/Poseidon and Jason-1 Satellite Altimetry Data, Geodesy for Planet Earth, Kenyon S., Pacino M. Ch., Marti U. (eds.), Berlin, Heidelberg: Springer-Verlag, 2012, pp. 833-841.

[12] Lebedev S.A., Mean Sea Surface Model of the Caspian Sea, Sovremennye problemy distantsionnogo zondirovaniya Zemli iz kosmosa, 2012, Vol. 9(3), pp. 224-234.

[13] Popov S. K., Modeling the Climatic Thermohaline Circulation in the Caspian Sea, Meteorology and Hydrology, 2004, Vol. 5, pp. 76-84.

[14] Lebedev S.A., Flood Wave Propagation Model for the Caspian Sea Based on Satellite Altimetry Data, Intern. J. Water Technology, 2012, Vol. 2(1), 12 p.

[15] Lebedev S.A., Kostianoy A. G., Interannual Variability of Water Exchange Anomalies Between the Northern, Middle and Southern Caspian Based on Satellite Altimetry Data, Ecologica Montenegrina, 2019, Vol. 25, pp. 106-115. 